\title{
EL VERSO LIBRE EN LA POESÍA DE JOSÉ LEZAMA LIMA. TRES CASOS ESPECÍFICOS
}

\author{
THE FREE VERSE IN JOSÉ LEZAMA LIMA'S \\ POETRY. THREE SPECIFIC CASES
}

\section{O VERSO LIVRE NA POESIA DE JOSÉ LEZAMA LIMA. TRÊS CASOS ESPECÍFICOS}

\section{Franco Navarro Pérez}

Universidad Nacional Mayor de San Marcos franco.navarro1@unmsm.edu.pe. ORCID: 0000-0001-6156-5142

Recibido: $12 / 03 / 21$

Aceptado: 25/03/21

* Estudiante de Literatura en la UNMSM, quien actualmente se encuentra próximo a cursar el noveno semestre de dicha carrera profesional. Fue miembro adjunto del grupo de investigación, también perteneciente a la mencionada casa de estudios, llamado LIGECU: Literatura, Género y Cultura durante el periodo 2018 - 2019. Ha participado en diversos coloquios organizados por la Casa de la Literatura Peruana y tiene publicado un relato corto en la revista sanmarquina Resistencia: Revista Plural de la Comunidad Universitaria. 


\section{Resumen}

Este artículo estudia los elementos que configuran el verso libre en la poesía de Lezama Lima desde el enfoque teórico de la versología moderna. La hipótesis postula que en su verso libre hay un retorno a las fuentes métricas de la antigüedad; es decir, el versículo, usando el emparejamiento y los grupos rítmicos semánticos. El trabajo desarrolla el análisis estructural desde el plano formal en tres casos específicos: "Muerte de Narciso", "Rueda el cielo", "Hai kai en gerundio" y, finalmente, las conclusiones.

Palabras clave: José Lezama Lima, verso libre, versículo, poesía latinoamericana.

\section{Abstract}

This article studies the elements that make up free verse in José Lezama Lima's poetry from the theoretical approach of modern versology. The hypothesis proposes that in his free verse there is a return to metric sources of antitquity, that is to say, the ancient verse, using the coupling and semantic rythmic groups. The work develops the structural analysis from the formal plane on three specific cases: "Muerte de Narciso", "Rueda el cielo", "Hai Kai en gerundio" and, finally, the conclusions.

Keywords: José Lezama Lima, free verse, ancient verse, latinoamerican poetry.

\section{Resumo}

Este artigo estuda os elementos que compõem o verso livre na poesia do José Lezama Lima, a partir da abordagem teórica da versologia moderna. A hipótese postula qe em seu verso livre há um retorno às fontes métricas da antiguidade, ou seja, o versículo, por meio de emparelhamento e grupos rítmicos semánticos. O trabalho desenvolve a análise estrutural a partir do plano formal em três casos específicos: "Muerte de Narciso", "Rueda el cielo", "Hai Kai en gerundio" e, finalmente, as conclusões.

Palavras-chave: José Lezama Lima, verso livre, versículo, poesia latino-americana. 


\section{Introducción}

En el presente trabajo se realiza un análisis de tres poemas de Lezama Lima desde el enfoque teórico de la versología moderna. Uno de los principales motivos de esta investigación es ampliar los estudios en torno a su poesía, teniendo como base el análisis del plano formal. En este sentido, consideramos pertinente aproximarnos a estos textos con la finalidad de demostrar su importancia dentro de la conciencia escritural del mencionado poeta cubano. Asimismo, servirán de principal sustento para la hipótesis que hemos planteado: demostrar que en la lírica lezamiana se ostenta una fórmula de composición, la cual vendría a ser una amalgama de las medidas tradicionales con el versolibrismo.

Tres son los apartados: recepción de la crítica, marco teórico y el análisis de los tres poemas. En el primero se ha tomado en cuenta los estudios académicos que se han identificado en la estética neobarroca de Lezama Lima: una proclividad a desatar el poder renovador de la palabra y elaborar imágenes metafóricas que generan un denso campo semántico. Estos estudios consideran que Muerte de Narciso es la piedra angular de la obra lezamiana, mientras que Enemigo rumor continúa con el legado, pero apuntando hacia la concepción de lo metapoético. Además, una constante evidenciada en dichos libros es la aparición de los elementos del agua y fuego como fuerzas naturales y poéticas, vinculadas a un deseo obsesivo del conocimiento. Es por ello que en el imaginario del poeta cubano se observa un vasto repertorio de símbolos y significados, siendo así una de las voces fundamentales de la tradición literaria latinoamericana.

En el segundo apartado se aborda el marco teórico concernientes a las nociones de la versología moderna. Entre los conceptos que destacamos para nuestra lectura, han sido el ritmo interior propio, el emparejamiento distribuido en las equivalencias sintácticas y semánticas, la escansión, los grupos rítmicos, 
los paralelismos y el encabalgamiento. Además, retomamos el debate sobre los antecedentes del versolibrismo. Esta discusión nos permite entender que en base a determinados sucesos que influyeron en la poesía moderna, la tradición métrica no se halla tan alejada de la propuesta del verso libre. Se vislumbra entonces que el afán rupturista de la vanguardia no fue tan radical como generalmente se piensa.

En el tercer apartado, se analizan los poemas "Muerte de Narciso", "Rueda el cielo" y "Hai kai en gerundio" desde las características de su forma. Las herramientas teóricas brindadas por la versología moderna aplicadas en los tres textos proporciona nuevas luces sobre la propuesta artística de Lezama Lima en el ámbito de la poesía. Una de las principales reflexiones que se desprende del análisis radica en cómo el poeta cubano hace uso de diversos tipos de versos, lo cual implica que hay un amplio conocimiento de la métrica clásica y, a su vez, del verso libre imperante todavía en su época. Por lo tanto, es posible denominar a la escritura poética lezamiana como profundamente heterogénea, logrando articularse a través de la resemantización y actualización las medidas de la antigüedad.

\section{Recepción de la crítica}

José Lezama Lima es uno de los escritores latinoamericanos más importantes de la centuria pasada. En su extensa obra encontramos la publicación de novelas, ensayos y poemas. Debido a la pluralidad de su pluma, la crítica literaria ha ido estudiando al bardo cubano desde sus primeros textos a los últimos y póstumos, divisando a partir de ello la articulación de un universo de imágenes, metáforas y símbolos vinculadas a su país natal y a la identidad del sujeto latinoamericano. Lezama Lima es, en este sentido, una figura fundamental en las letras castellanas y, por ende, del imaginario de este lado del mundo.

La travesía poética lezamiana se inicia con Muerte de Narciso, saliendo en circulación el año 1937. Este libro, constata- 
do principalmente en el poema homónimo, "Muerte de Narciso" deja en claro lo que Lezama Lima entiende al poema según su función totalizadora, es decir, como un texto creador de infinitas posibilidades. Paralelo a su carácter cosmogónico, este libro presentó la "máxima, expresión, el ritmo y la luz" de las expresiones artísticas de post vanguardia (Ehrmannová, 2016, p. 14). En este sentido, llegó a ser apodado como el nuevo Góngora; debido a la articulación de una sintaxis caracterizada su juego críptico de frases y un empleo original de figuras literarias. De este modo es que también se advierte su afán por desatar el poder innovador de la palabra. Por lo tanto, para situar al poeta cubano en el horizonte estético-literario, consideramos necesario precisar la propuesta artística del neobarroco. Lo remarcable del poemario en cuestión es que, dada la fecha de su publicación, antecede relativamente a lo que se entiende como los alcances que consiguió el neobarroco durante el contexto de la postguerra. Los efectos de la segunda guerra mundial desataron una inquietud temporal e histórica, incitando a que se replanteen las categorias (Diaz, 2015). Ligado a lo anterior, se podía observar que la cultura humanista burguesa, junto a las lógicas vanguardistas empezaban a agotarse.

De manera que esto implicó emprender un viraje que consista en actualizar la tradición. El barroco, cuyo apogeo fue durante todo el siglo XVII, atrajo la atención de los artistas de mediados del siglo XX; quienes llegaron a comprenderlo como oscurecimiento, metalenguaje, vocablo elusivo y, principalmente, como un revival (Díaz, 2015), como el punto de partida para la refundación, para una nueva dinámica cultural. Por extensión, el barroco era el establecimiento de una "salida" para el arte del presente. La urgencia de revitalizar las herramientas de lectura que permitieran englobar a la filosofía, ética, epistemología y a las demás dimensiones del pensamiento suscitaba el planteamiento de lo neobarroco. Este concepto que caracteriza a la época contemporánea, a su vez, despliega el "ritmo y la repetición, el límite y el exceso, el detalle y el fragmento, la 
inestabilidad y la metamorfosis, todo esto en un caos y laberinto donde predomina la dispersión y, especialmente, la complejidad" (Ehrmannová, 2016, p. 12). Y Muerte de Narciso se inscribe en estas acepciones, tal como hemos señalado líneas más arriba, muchos antes de que se comenzara la plena teorización de este nuevo sistema estético-ideológico.

Paralelo a esta lectura, debemos referirnos a los apuntes de Severo Sarduy en Ensayos generales sobre el barroco (1969). Dicho libro, desde un punto de vista filosófico y cosmológico, señala que el neobarroquismo, mediante la substitución, condensación y proliferación logran hacer énfasis en lo intertextual y paródico de los textos. El barroco, siendo un medio de los dibujos circulados, desviados del centro, buscan la armonía y homogeneidad a partir de Dios o sin este. No obstante, el Neobarroco ha perdido este Dios, refleja solamente contrariedad y suspensión. La base del neobarroquismo es, de este modo, una proyección del deseo que no puede tocar su objeto y, a su vez, la tendencia por atrapar lo que constantemente se escapa. Tanto el barroco como el neobarroco, sedimentaron vías a través de las cuales el lenguaje luce más real, mientras que el texto vendría a corresponderse con la ilusión.

Es posible identificar los caracteres mencionados en el primer poemario de Lezama Lima: la propuesta de un proyecto artístico a largo plazo. El poema homónimo, "Muerte de Narciso", se distingue por la rareza, la dificultad de su lectura y, simultáneamente, por su fragua de versos que constituyen el propio acto de la escritura en base a la compleja concepción de imágenes. Si bien es cierto que en la poesía lezamiana predomina el hermetismo, este trasciende del proceso sintáctico y del material verbal oscuro, razón por la cual el hermestismo lezamiano podría catalogarse como una manera del ser (Ehrmannová, 2016). "Muerte de Narciso" anuncia de la idea de la muerte desde el título y opera como eje constante en la presentación de los versos. No obstante, el poema no promueve la recodificación de todo el mito, solo la de "su porción última al modo barroco de 
la sobremanera" (Santos, 2011, p. 28). Debajo de la exuberante puesta en escena de los vocablos, se oculta una minuciosa representación de los momentos finales de Narciso.

El texto de Lezama Lima no se limita a establecerse como una representación mimética de la realidad, sino que abre las puertas para la creación de una nueva partiendo de "la exploración constante de lo desconocido" (Santos, 2011, p. 28), como si desplegara una "abierta red de relaciones [que] trabaja una estructura que se desprende casi totalmente de las habituales y canónicas asociaciones para alumbrar un camino hacia el nacimiento mismo de las cosas" (Santos, 2011, p.28). De este modo, es posible inferir que del caos se puede producir vida, y viceversa. Pareciera que la muerte y la resurrección son términos disímiles, pero, finalmente, alcanzar a entablar un vínculo mediante el cual se complementan.

Otro aspecto para considerar en "Muerte de Narciso" es, que siendo el poema fundador lezamiano, apuntó a la muestra de "un constante deseo de sabiduría" (Santos, 2011, p.28). En otras palabras, ese sería el objetivo primario de la creación, ligado con la búsqueda incesante de lo posible desde un diálogo heterogéneo de culturas. El encuentro entre América y Occidente - el componente americano es la interpretación de Lezama Lima, mientras que Narciso constituye el elemento mítico de la tradición grecorromana- denota también la oportunidad para conjugar estilos y estructuras. No hay estrechos limites que no se puedan superar, y los inmedibles alcances de la creación poética lo constata.

Narciso es, en tal sentido, un personaje que ha sido material para la poesía desde la concepción de su historia o de su mito. Pero lo que separa a Lezama Lima de autores consagrados como Ovidio o Paul Valéry, reside en abordar al símbolo de la belleza egocéntrica desde el poder transformador de la palabra (Ríos, 2011). De modo que puede advertirse que en su poema se encuentra y se mezcla lo clásico, lo neobarroco, lo simbolista y lo cubano. Captura el mundo y la realidad transmutándola 
mediante el juego de reflexión (Ríos, 2011) entre el sonido, la palabra y el simbolo. Poesía equivale, entonces, al motor que transforma el mundo, aquella en la que es posible reconstruir y recrear la realidad. Se logra percibir que el poema, en sí mismo, se convierte en un objeto de extrañamiento (Ríos, 2011). Deviene en un signo criptico, donde la opacidad del lenguaje y su heteronomía son llevados, en apariencia, a un nivel exacerbado. Lo que se empeña por expresar el lenguaje se torna difuso y escurridizo en el texto lezamiano. El lenguaje, entonces, deja de tener esa capacidad "sígnica" y procede a poseer una capacidad simbólica per se, generando entonces vasos comunicantes entre los principios estéticos del simbolismo y el neobarroco. El valor agregado a la retórica desaforada, a la profusión de ornamentos viene a ser su conversión en el símbolo o lógica míticos.

La formación de un logos que opera en función al mito se articula en los elementos del fuego y del agua cuya relación produce un oxímoron de la vida, la muerte y el renacimiento (Ríos, 2011). En primer lugar, el agua vendría a ser uno los símbolos fundamentales del poema, dado que se manifiesta en las operaciones del espejo. En el poema lezamiano el agua cumple la función de ser el material en que se refleja Narciso; el agua connotaría la muerta y la regeneración: sería el espacio para la abolición de la realidad y para su posterior surgimiento. Esto se debería a que el agua es un espacio de tránsito entre diversos planos de conciencia o de la realidad: es querer obtener la trascendencia a través de la reflexión y el conocimiento. Narciso se devela en su propia mirada proyectándose en la fuente.

Por su parte, el fuego estaría representado desde su dimensión sexualizada, como expresión, simultáneamente, del erotismo y de la introspección (Ríos, 2011). En tal sentido, contemplar al fuego de esa manera implica la idea de que es el elemento integrador de la realidad: el fuego sexualizado es la fuerza cósmica que une y disgrega, que pone en contacto los planos de la existencia partiendo de las posibilidades del ser. La carga ontológica del poema lezamiano remitiría, desde el elemento del 
fuego, a un erotismo nacido del juego de seducción reflejo y recíproco. Bajo este examen, el autoerotismo muestra en "Muerte de Narciso" una búsqueda de la perfección. Lo original de la actualización lezamiana de este mito supera las lecciones del amor egoísta para elevarlo como una vía para conocerse a sí mismo (Ríos, 2011). La muerte simbólica de Narciso implica proseguir el camino heroico de la transformación, cuya meta final es la redención y el renacimiento.

Se ha destacado, también, la importancia de lo visual en "Muerte de Narciso". Es decir, las operaciones de la imagen dentro de la construcción poética. En el texto lezamiano, las imágenes se urden a partir de un uso minucioso de la metáfora. No obstante, no es posible advertir el concepto clásico de metáfora en el poema, tal como lo había postulado Aristóteles -metáfora como especie de añadido al lenguaje común para darle gracia, hacerlo más asequible, entre otros. La metáfora empleada por Lezama Lima se aproxima más al "concepto romántico" (Chamorro, 2009, p. 14), porque, así como en el romanticismo, se busca un orden y una armonía desde lo misterioso. Si bien es cierto que deben salvarse las diferencias entre estas dos posturas artísticas, cabe añadir que la dicha figura literaria se impulsa, como fuerza renovadora, a través de la combinación de muchos factores en el orden creativo; es decir, pertinentes a lo que se comprende por fragmentos de la imagen (Chamorro, 2009).

De este modo, Lezama Lima viene a apostar por una creación separándose de la tradición para renovarla (Chamorro, 2009). Asimilar culturalmente los distintos relatos míticos le permite revalorizarlos y atribuirles un nuevo repertorio de significados. En este sentido, la imagen poética de "Muerte de Narciso" es la de un ser que se sabe imagen, pero a su vez reconoce en ella el yo tangible, logrando así el orden de las posibilidades. La imagen en base a la metáfora lezamiana es aquella que hila los fragmentos de la Imagen, es la que transforma las diferencias en semejanzas, la que "une lo cognoscible con lo incógnito 
tanto en el lenguaje como en sus expresiones poéticas, similar a lo que sucede en la propia cotidianidad del hombre" (Chamorro, 2009, p. 15).

En suma, la imagen de Narciso, en la pluma de Lezama Lima, es la imagen del mito en la historia, traída por el poeta mediante el poder renovador que posee la metáfora. En él es posible advertir la convergencia de las reminiscencias de una armonía perdida debido al caos de la modernidad, lo cual hace que el poeta pueda alcanzar fragmentos de aquella naturaleza con la intención de recuperarla desde el arte lírico. Es Narciso, de esta forma, el eterno buscador de la imagen que lo abarca, pero también es a quien se le escapa en la fluidez de lo insondable (Chamorro, 2009). La necesidad de Narciso por encontrar su yo en el reflejo se interpreta como una alegoría de la búsqueda incesante del hombre por su esencia que, a su vez, ha suscitado intriga y sospecha a lo largo de la humanidad.

La trascendencia que alcanzó Muerte de Narciso entre los lectores y la crítica fue continuada por el libro Enemigo rumor, publicado en 1941. A ambos se le han catalogado como "las obras cruciales que influyeron toda la generación de los poetas jóvenes" (Ehrmannová, 2016, p. 16); es así como Lezama se convirtió en un ídolo de la generación joven fascinada por su erudición. Bajo este juicio, añadimos que en el par de poemarios hay una tendencia del poeta por acercarse al espejo tratando de entablar un intento de encuentro material. Entonces, si pensamos ello desde el plano metafísico, se traduce como un deseo posesivo de conocimiento, mas, nace frustrado, ya que no concluirá en una creación; porque "la poesía, cual enemigo rumor, no se deja atrapar, se escapa en el instante en el que alcanza su mejor definición” (Del Río, 2005, p. 1999).

La resonancia que tuvo Enemigo rumor fue en parte por la consolidación del modo de decir lezamiano, el cual, en otras palabras, rompía los cánones de aquella época no solamente en un sentido puramente estético, sino también por un trasfondo de ideas en el que la propia poesía se tornaba objeto de 
indagaciones metafísicas, acompañada de un despliegue verbal sin precedentes (Portuondo, 2003). Asimismo, se plantea la cuestión de lo metapoético que opera junto a sus signos líricos, produciendo una mirada un poco más vigilante sobre el libre discurso poético, lo que quiere decir que se concibe la realidad con la poesía implícita en ella que prima por sobre las cuestiones afectivas o sentimentales (Portuondo, 2003). De este modo, la postura estética lezamiana configurada en dicho poemario apunta a explorar el sistema del lenguaje, ya sea desde la dimensión del sonido o la del significado.

En Enemigo Rumor también se ha podido identificar un "problema entre la fijeza y la evaporación" (Fernández-Cozman, 2001, p. 102), como si la escritura del poeta quisiera capturar un instante, pero sin lograrlo, lo que resulta en una metamorfosis de las imágenes poéticas. Paralela a esta precisión, se advierte que el agua es uno de los elementos cruciales en el libro, representándose como una "agua discursiva que configura una imagen de quietud, pues hay un paisaje inmóvil y, por lo tanto, una ausencia de movimiento" (Fernández-Cozman, 2001, p. 103). Por ese motivo es que el agua es multifuncional: opera como sinónimo de mansedumbre, como una reconstrucción de la imagen del yo en el espejo y como posibilidad de la reconstrucción de los tiempos pasados.

De otro lado, a lo largo del libro, Lezama Lima emplea la imagen del fuego partiendo de la premisa de que posibilita la comunicación y que manifiesta el intercambio de la palabra entre el yo y el otro. Entonces, la interacción entre los elementos mencionados suscita la idea que consiste en emprender la búsqueda del lado mítico del universo, dado que el fuego, como lo masculino, con el agua, como lo femenino, se complementan en el tejido del lenguaje. En otras palabras, se consigue comprender que "el fuego le pasa sus semas al agua y el agua hace lo mismo con el fuego. El dominio del fuego recibe el contenido intuitivo y sensible que le da del dominio del agua" (Fernández-Cozman, 2001, pp. 106 - 107). 
El breve repaso por las exégesis de sus dos primeros poemarios nos conduce a ciertas reflexiones, como, por ejemplo, que Lezama Lima hizo prevalecer la creación de la imagen desde lo simbólico y la metáfora hermética. Hay en sus versos una intención por desplegar el poder creador de la palabra rebosando sus límites, motivo por el cual, se advierte el empleo recurrente de los elementos naturales concebidos dentro de su sistema poético.

\section{Marco teórico. Alcances y limites de los estudios sobre el versolibrismo}

Desde fines del siglo XIX hasta mediados del siglo XX, la poesía emprendió una búsqueda incesante de nuevas formas de expresión. Ello se debe a que el poeta, específicamente, el de vanguardia, aducía que los límites de las métricas tradicionales le impedian gestar un verso liberado, en aras de la innovación estético-verbal. Al ritmo consonante y al número determinado de sílabas - por mencionar algunos caracteres del verso clásico- se le opuso la propuesta artística de la palabra como unidad que quiere desligarse de la norma métrica para canalizar la subjetividad total del poeta, es decir, un ritmo interior propio (Utrera Torremocha, 2003). Aquel fenómeno histórico-cultural, es decir que poseyó como consigna la libertad y el deslinde con el logos de la época, tuvo un fuerte influjo en todas las manifestaciones del arte, proclamando el agotamiento de las maneras tradicionales y cediendo el paso a ese indetenible afán de ruptura. Así es como se desata, en las primeras décadas de la centuria pasada, la plenitud del verso libre.

Partiendo desde el enfoque de la versología moderna, el verso libre ostenta como base de su creación generalmente a la experimentación lingüística, cuya finalidad apunte a que la prosodia, la sintaxis y la espacialidad se dinamicen. Esto vendría a generar un verso iconoclasta, disforme y desafiante a la teoría formal de la lírica (Belic, 2000). A lo precedente, debemos agre- 
gar que, dentro de la propia experimentación entra la idea de que el verso se libere del corsette de la forma métrica del soneto, del alejandrino, entre otras manifestaciones líricas tradicionales. No obstante, cabe recordar que versos mayores a catorce sílabas tienen su antecedente en el versículo, el cual fue clave para la literatura hebraica y la constitución de la Biblia (Henríquez Ureña, 2003). En tal sentido, una parte fundamental de la raíz del versolibrismo está constituida por los paralelismos identificados en lo oral y lo popular que, en otras palabras, vendrían a ser las manifestaciones más arcaicas de índole sonora.

Estos apuntes guardan cierta relación con lo postulado por Ricardo Jaimes Freyre en sus Leyes de la versificación castellana (1912). El poeta diseña una sistematización del verso libre, refiriéndose a este como verso polimorfo, un verso sin ritmo o arritmo. Lo destacable de esta definición es que se atañe al asunto de la libertad y a la cuestión de que en su esqueleto se combinan todos los periodos prosódicos con una sola idea o imagen. De esto se infiere que cada pensamiento crearía su propia forma. Además, considera como antecedente el ritmo ideológico de los hebreos, árabes, chinos, entre otros, y a los versículos que son herencia del libro de San Jerónimo. Sin embargo, creemos pertinente oponer, a estos apuntes, otra postura analitica de lo que se entiende del versolibrismo.

Hay una postura que consiste en comprender que la manifestación del verso libre tendría como raíz - o precursor-al verso tridecasílabo (Jauralde, 2004), debido a que este ostenta una tendencia a la irregularidad. En tal sentido, la esencia del verso libre sería comprendido como un verso de difícil acoplamiento a los ritmos clásicos, tomando un verso que le sirve de patrón. Por lo tanto, el verso libre resultaría de una de suma o mezcla (Jauralde, 2004) de versos regulares, versículos y versos irregulares. De esta lectura se colige que habría la existencia de un programa estético, es decir, una conciencia de escritura vinculada con la intercalación de versos de diversos tamaños. 
Bajo esta línea, se añade también la idea de entender al verso libre teniendo en cuenta que en esta composición poética siempre se podrá advertir la presencia de una reiteración de versos y ritmos (Jauralde, 2004). Por lo tanto, si se prescindiera de esta observación, se aceptaría al versolibrismo como forma de expresión que también implicaría aceptar la presencia esporádica de versos cuya escansión develarían diferentes medidas, lo cual no obedecería a un patrón rítmico desconocido y sería no relevante extenderse hasta el versículo. Lo precedente incita a pensar que sería mejor mantener la coherencia sintáctico semántica que hablar de ritmo de pensamiento (Jauralde, 2004), porque este se encontraría ubicado en un lugar impropio.

A continuación, nos prestaremos de otro planteamiento teórico que nos sirva de contraste a lo anteriormente señalado. Resulta factible enfatizar la relación de la versificación teniendo como base el ritmo de pensamiento, el verso de imágenes acumuladas o yuxtapuestas libre, donde se emplea una reiteración de imágenes $\mathrm{y}$, principalmente, la metáfora, que es frecuente en la vanguardia (Paraíso, 2000), a lo que se podría acotar que también durante la post vanguardia, tal como se ha podido identificar en la composición lírica "Muerte de Narciso". Entonces, cuando en el poema se advierten imágenes encadenadas, repeticiones obsesivas de determinados elementos, encabalgamientos o juego de tensiones, estaríamos hablando de la denominada equivalencia afectiva de imágenes (Paraíso, 1985).

Del ritmo poético es posible señalar dos tipos de factores: semánticos y sintácticos. Estos se hallan vinculados con la versificación paralelística (Paraíso, 2000), apoyada en el ritmo de pensamiento. El factor semántico implicaría un retorno ideológico, sea en forma negativa (paralelismo sinonimico), en forma negativa (paralelismo antitético) o en forma de emblema o símil (paralelismo emblemático). Por su parte, el factor sintáctico se evidencia las recurrencias sintácticas (quiasmos, paromoeosis), en recurrencias léxicas (anáfora, repetición, complexión), y en recurrencias semánticas (enumeración, acumulación, si- 
nonimia). En este sentido, ambos estarian destinados a explicar la poeticidad de los textos poéticos (Paraíso, 1985). Acaso determinar las constantes de la subjetividad propia, o el ritmo interior, evidenciaría la complejidad del ejercicio de la creación lírica e implicaría partir desde un examen ontológico.

En sintonía con lo anterior, consideramos factible para nuestra investigación las anotaciones teóricas respecto a la pausa métrica. A modo de breve contexto, debemos anotar que aún resulta difícil separar el cambio de renglón de la idea de pausa, puesto que, en los últimos siglos, ha sido denominado como marca convencional (Martínez, 2019). Por lo tanto, que haya la presencia de pausas versales provoca una segmentación no natural, lo cual convencionalmente se marca con un cambio de línea. En este sentido, en el versolibrismo se hace uso de estas divisiones gráficas, suscitando la discusión tanto de su valor literario como lírico, aunque, y esto es medular, sería posible advertir una intención del autor y una disposición del lector (Martínez, 2019). Nuevamente, esta precisión se acerca a lo que entendemos como conciencia de la escritura poética, que puede vincularse con el tema de la distribución del espacio.

Además, en el verso regular y en el libre, la separación gráfica suele venir motivada por dos criterios: uno rítmico, y el otro semántico (Martínez, 2019). En el primero, su demostración recae en la elaboración de estructuras silábico acentuales y de paralelismo, mientras que en el segundo se lo identifica en la presencia de encabalgamientos en el verso libre. Entonces, lo que se colige es que los versos, para integrarse como una de las diferencias esenciales de la prosa, deben poseer entonación y estar delimitados por pausas (Martínez, 2019). En suma, la pausa se configura como la única marca rítmica o el único elemento fundamental cuya permanencia estaría desde el verso más tradicional hasta el verso de vanguardia de mayor intención rupturista.

Es menester también referirnos al coupling o emparejamiento, el cual, en primera instancia, denota la posibilidad de 
aislar un fenómeno cohesionador suponiendo el principio estructurador del lenguaje poético (Pozuelos, 1989). En este sentido el coupling implica la ubicación de elementos lingüísticos equivalentes en posiciones de igual equivalencia o, al revés, el uso de posiciones equivalentes como desgaste de elementes fónicos o semánticos que se equivalen entre sí (Pozuelos, 1989). La equivalencia semántica comprende la relación de miembros de un paradigma o clase, es decir, la constitución de un orden de realidad semejante y/o opuesto y la equivalencia fonética concierne a la elaboración de rimas, aliteraciones, repeticiones sonoras, la idea de acabar dos vocablos en una misma consonante, etc.

Retomando lo del ritmo interior, debemos ubicarnos en el contexto de la tradición poética occidental para hallar los antecedentes del versolibrismo. Estos vendrian a ser el juego métrico, la recuperación y adaptación de versos, y los versos de carácter bíblico que, dicho de otra manera, es el versículo señalado en párrafos anteriores-, aunque los principales estimulantes para el cambio fueron el verso de carácter prosaico de Whitman y el poema como un sinnúmero de posibilidades del simbolismo francés (Torremocha, 2003). Se habla ya de una travesía hacia la libertad expresiva, personal para cada uno, lo cual logró desatarse un enfrentamiento entre lo viejo y lo nuevo - conflicto que, con el transcurrir de los años, logró acarrear una situación relativamente paradójica.

De los simbolistas franceses, rescatemos que ellos consideraron a la prosa poética como un paso previo al verso libre. Ello es una muestra de la individualidad, una creación ligada al ritmo interior, al ritmo de pensamiento con el aspecto sintáctico. Entonces, la construcción del verso estaría basada en la idea, lo que antes, en el verso clásico, no era permitido: la construcción de la idea se basaba en la rigurosidad métrica - soneto, alejandrino, etc.- (Utrera Torremocha, 2003). Se colige pues, que cuestionar esta rigidez implicó problematizar los recursos 
tradicionales, pero, a su vez, incitó a que se amplíen los propios estudios de la versología.

Por esto mismo es que resulta pertinente tomar en cuenta la propuesta de estudiar al versolibrismo como un acontecimiento estético dentro de los marcos de la historia. Si es que el verso libre fue una innovación literaria, debemos comprender de qué manera fue recibida por el público, sea aceptándola o rechazándola. Ello se vincula con el lector y sus expectativas, puesto que este sujeto receptor debe advertir, por lo menos, en la tipografía del verso libre una versalidad suficiente, es decir, reconocer el remanente que provendría del verso clásico (Utrera Torremocha, 2004). En otras palabras, y es lo que se podrá ver en el apartado siguiente en torno a Lezama Lima: el versolibrismo no es del todo autónomo. Su identidad mostraría antecedentes en la tradición métrica.

Lo precedente se relaciona con que el verso libre protagoniza una ruptura estético-cultural dentro de un periodo histórico determinado, pero no absoluta: en su misma concepción se evidencian ciertos elementos que conforman la estructura del verso clásico. En este sentido, la irrupción del versolibrismo vendría a ser un conjunto de reformas en la esfera de la poesía (Utrera Torremocha, 2004). Y ello se puede sustentar en dos puntos: el verso libre se presta de ciertos engranajes de la lírica tradicional para renovarlos y lo segundo sería que, tras la declinación de la vanguardia, los poetas se sintieron propensos a emprender un viraje hacia las formas clásicas, de las que quería deshacerse la misma vanguardia.

Actualizar el debate respecto a los orígenes del verso libre brinda la oportunidad de asentir o discrepar con lo que se ha postulado. No obstante, bajo el contexto literario latinoamericano de la centuria pasada, consideramos que, tras la vanguardia desatada, algunos autores buscaron retornar a la tradición o nutrirse de ambas fuentes, lo cual es posible constatar en la escritura poética de José Lezama Lima, tal como veremos posteriormente. 


\section{El verso libre en la poesía lezamiana. Tres casos}

En el presente apartado se procederá a elaborar el análisis de los poemas "Muerte de Narciso", "Rueda el cielo" y "Hai kai en gerundio" desde el enfoque de la versología moderna. Principalmente se tomará en cuenta el concepto de las equivalencias fonéticas y semánticas, el ejercicio de la escansión y el esquema de los grupos rítmicos en función del propio ritmo interior. En suma, el estudio residirá en esbozar una aproximación de dichos textos teniendo en cuenta la elaboración la forma y, en parte, el estilo.

\section{El caso de "Muerte de Narciso"}

El texto insignia del poemario debut de Lezama Lima, distribuido en grupos de ocho líneas cada uno, se constituye en 136 versos. Ante su gran extensión, hemos considerado pertinente seleccionar tres fragmentos específicos. El primero viene a ser la sección de apertura, la cual también funciona como el exordio, dado que el poema también ostenta un carácter narrativo basándose en símbolos:

v.1 Dánae teje el tiempo dorado por el Nilo $\mathrm{x} \mathrm{x} / \mathrm{x} \mathrm{x} / \mathrm{x} \mathrm{x} / \mathrm{x} \mathrm{x} \mathrm{x} / \mathrm{xx} \dot{x} \mathrm{x}$

v.2 envolviendo los labios que pasaban $\mathrm{xxx́x/xx́x/} \mathrm{xxx́x}$

(13 silabas)

(11 silabas)

(11 silabas)

v.3 entre labios y vuelos desligados. $\mathrm{xxx́x}$ / xx́x/ xxx́x

v.4 La mano o el labio o el pájaro nevaban. (11 sílabas) $\mathrm{x} x \dot{x}$ / ́xx/ ́́xx/ xx́x

v.5 Era el círculo en nieve que se abría. $\mathrm{xxx́xx/} \mathrm{x́x/} \mathrm{xxx́x}$

(11 silabas)

v.6 Mano era sin sangre la seda que borraba X́x/ xxx́x/ xx́x/ xxx́x

v.7 la perfección que muere de rodillas $\mathrm{xxx} / \mathrm{xx́} \mathrm{x} / \mathrm{xx} \mathbf{x}^{\mathrm{x}}$

v.8 y en su celo se esconde y se divierte. $\mathrm{xxx́x} / \mathrm{xx́x} / \mathrm{xx} x^{x} \mathrm{x}$

(13 silabas)

(11 sílabas)

(11 sílabas) 
A través del ejercicio de la escansión, podemos notar que hay una predilección por los endecasílabos y el diseño de un verso poco usual, el tridecasílabo. El poeta cubano, entonces, aún mantiene la utilización de medidas tradicionales. Este hecho nos advierte que su abordaje del mito parte desde una distribución armónica, casi simétrica de sílabas. Por su parte, la identificación de sus grupos rítmicos arroja hechos que merecen ser examinados. La cuestión prosódica nos hace notar el predominio del grupo "xxx́x". El despliegue de esta fuerza acentual provoca en la estrofa una minuciosa sensación de cadencia, lo cual se halla en función del encabalgamiento y de los versos que terminan en un punto; o sea, una unidad de sentido completo. Es por esta razón que detectamos la presencia de paralelismos en los grupos rítmicos de los versos 2, 3 y 8. Del " $x x x x$ " es posible agregar que configuraría la coherencia sonora de la estructura la estrofa. Destacamos también a la continua alusión de los "labios" desde el verso 3 hasta el verso 4 e, inclusive, las referencias a la "mano" y a las "rodillas". El recurso metonímico (parte-todo) opera, a su vez, como una sucesión de imágenes equivalentes. El campo semántico de dicha palabra se vincula con la cuestión del coupling. En tal sentido, prestar atención a la reiteración de figuras ocasiona divisar que, en este fragmento del poema, se enfatiza el aspecto de lo corpóreo y lo visual.

Prosigamos con la segunda sección, donde se perciben ciertos cambios tanto a nivel formal como semántico:

v.65 Triste recorre — curva ceñida en ceniciento airón-

$$
\text { X́x/ xx́x/ x́x/ xx́x/ xxx́x/ ́́x }
$$

(16 sílabas)

v.66 el espacio que manos desalojan, timbre ausente

$$
\mathrm{xx} x \dot{x} / \mathrm{x} \dot{x} \mathrm{x} / \mathrm{xx} x \dot{x} \text { / x́x / ́́x }
$$

(15 sílabas)

v.67 y avivado azafrán, tiernos redobles sus extremos.

$$
\mathrm{xx} \dot{x} \mathrm{x} / \mathrm{x} \dot{x} / \mathbf{x} \mathrm{x} / \mathrm{x} \dot{x} \mathrm{x} / \mathrm{xx} \mathbf{x} \mathrm{x}
$$


v.68 Convocados se agitan los durmientes, fruncen las olas $\mathrm{xx} x \dot{x}$ / $\mathrm{x} x \dot{x} / \mathrm{xx} x \dot{x}$ / $\mathrm{x} \mathrm{x} / \mathrm{x} \dot{x} \mathrm{x}$

(16 sílabas)

v.69 batiendo en torno de ajedrez dormido, su insepulta tiara.

$$
\mathrm{xx́x} / \mathrm{x} \mathrm{x} / \mathrm{xxx́} / \mathrm{xx́x} / \mathrm{xx} x \dot{x} / \dot{x ́}^{\mathrm{x}}
$$

(17 sílabas)

v.70 Su insepulta madera blanda el frío pico del hirviente cisne.

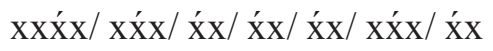

v.71 Reluce muelle: falsos diamantes; pluma cambiante: terso atlas.

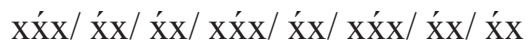

(18 sílabas)

v.72 Verdes chillidos: juegan las olas, blanda muerte el relámpago en sus venas.

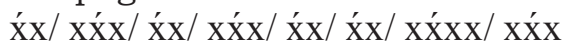

(21 sílabas)

Tal como se puede observar, el poema emprende un traslado progresivo del verso libre al versículo. Por lo tanto, en este caso, la concepción del versolibrismo es usada desbordando sus propios limites. A esto es necesario añadir que se hace un empleo de las medidas antiguas desde el punto de vista moderno. Entonces, de lo precedente se puede colegir que una de las primeras innovaciones de Lezama Lima resemantizando al mito de Narciso, consiste en apartarse del uso del verso clásico y el libre, para retomar la métrica de la antigüedad. Asimismo, plantear esta intención artística concede al poeta la amplitud de las posibilidades expresivas concernientes a lo lírico partiendo de su propio ritmo interior. Atisbamos también en el fragmento el uso recurrente tanto del grupo rítmico " $\mathrm{xx}$ 'x" como del "x́x". Se advierte la persistencia por apuntar a que el poema muestre una sonoridad en relación con la frecuente utilización del acento grave. Otro aspecto para considerar es la ausencia de paralelismos, lo cual podría explicarse en esta idea del desplazamiento del verso libre al versículo. La poca presencia de encabalgamientos — solamente detectados en los versos 66, 67 y 69 - refuerzan nuestra premisa. La irregularidad de los versos permite pensar que a la mayoría de los que constituyen 
la estrofa se le has atribuido una suerte de autonomía, una funcionalidad independiente o, como dijimos líneas más arriba, detentan un sentido propio. No obstante, es posible divisar dos equivalencias semánticas. La primera es un grupo que se corresponde con las imágenes de la naturaleza operando como metáforas — “olas", "relámpago", "cisne”, "diamantes", "azafrán”, "pluma"-, de modo que el criterio de clasificación vendría a ser la intensidad, pasando de lo delicado hasta lo mortal o imponente. Por su parte, la otra equivalencia pertenece a la cuestión auditiva — "redobles", "timbre", "chillidos". En tal sentido, la imagen poética se refuerza ya no solo mediante la mirada puesta en el exterior esbozando figuras que bordean lo pictórico; ahora se ponen de relieve los vocablos cuyo significado sean vinculados directamente con la idea del propio sonido.

Continuemos con el último fragmento citado para esta ocasión; en el cual, desde un primer momento, se logra advertir una estructura distinta a las anteriores; siendo, por eso mismo, poseedora de mayor complejidad:

v.113 Narciso, Narciso. Las astas del ciervo asesinado

$$
\mathrm{xx́} \mathrm{x} / \mathrm{x} x \dot{x} / \mathrm{xx́} \mathrm{x} / \mathrm{xx́x} / \mathrm{xx} \mathrm{x} \mathrm{x}
$$

(16 silabas)

v.114 son peces, son llamas, son flautas, son dedos mor disqueados.

(16 sílabas) $\mathrm{xx́x} / \mathrm{xx́x} / \mathrm{xx́x} / \mathrm{xx́x} / \mathrm{xx} x$

v.115 Narciso, Narciso. Los cabellos guiando florentinos reptan perfiles,

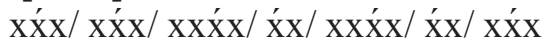

(21 sillabas)

v.116 labios sus rutas, llamas tristes las olas mordiendo sus caderas.

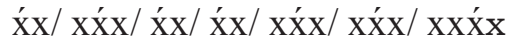

(19 sílabas)

v.117 Pez del frío verde el aire en el espejo sin estrías, raci mo de palomas

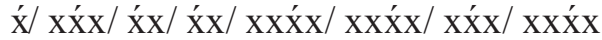

(23 sílabas)

v.118 ocultas en la garganta muerta: hija de la flecha y de los cisnes.

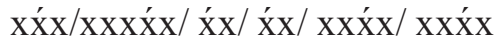

(20 sílabas) 
v.119 Garza divaga, concha en la ola, nube en el desgaire, X́x/ xx́x / '́x / ́́x / ́xx/ xxx́x

(15 sílabas)

v.120 espuma colgaba de los ojos, gota marmórea y dulce plinto no ofreciendo.

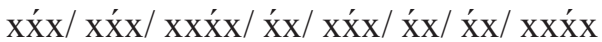

(23 sílabas)

En primera instancia, observamos el pleno despliegue de la modalidad del versículo. Como comentamos al principio de este apartado, el discurrir del poema sobresale por su componente narrativo, lo cual es logrado mediante el empleo del versículo. Además, se puede hacer énfasis en que Lezama Lima, para construir su poética, hace uso de un mito perteneciente a la tradición para reactualizarlo, no solamente en el fondo, sino también en la forma. Siendo consciente del legado clásico, propone darle una nueva vida al personaje de Narciso, el cual ha sido revisado por diferentes épocas influyendo en la manera de hacer poesía. Respecto a los grupos rítmicos, destacamos la relación del verso 113 con el verso 114 en base a su idéntica estructura. Se puede considerar que opera como una suerte de paralelismo; sin embargo, a esto hay que añadirle que la presencia del encabalgamiento entre estos dos versos suscita la impresión de simetría, como si hubiera una perfecta escisión, un "hemistiquio". Es remarcable el carácter anafórico del verso 113 y el 115, por donde se percibe un ritmo de imágenes encadenadas en torno a la cuestión de lo sensorial. La reiteración del nombre de Narciso induce a pensar que, tras la extensa descripción simbólica desatada en las estrofas precedentes, comienza a tomar protagonismo para la transformación final. Por último, resaltamos en el fragmento una equivalencia semántica concerniente a la idea de un bestiario. Este inventario de alimañas — “ciervo", "peces", "palomas", "cisnes", "garza”- se distingue porque la mayoría están ligadas al género de aves, de las que se estaría acentuando su color blanco, la acción del vuelo y la belleza aérea. En tal sentido, el aspecto de lo alado 
se configura con la intención de preparar el escenario definitivo para Narciso, terminando por fugar "en pleamar sin alas".

\section{El caso de "Rueda el cielo"}

Publicado en Enemigo rumor, específicamente localizado en la sección "Filosofía del clavel", nos aproximaremos a este poema tomando en cuenta la escansión y la dilucidación de los elementos que integran su forma. Como se podrá observar, la construcción poética de "Rueda el cielo" destaca por sus repeticiones y sus densas imágenes poéticas, los cuales son motivos estéticos y formales que también hemos señalado en el caso precedente. A continuación, presentamos el texto:

v.1 Rueda el cielo — que no concuerde x́x/ X́x/ $\mathrm{xxx} x$ x

v.2 su intento y el grácil tiempo$\mathrm{x} x$ x / ́x $\mathrm{x} / \dot{\mathrm{x} x}$

v.3 a recorrer la posesión del clavel $\mathrm{xxx} \dot{x} / \mathrm{xxx́} / \mathrm{xxx}$

v.4 sobre la nuca más fría $\mathrm{xx} \mathbf{x} \mathrm{x} / \mathrm{x} / \mathrm{x} \mathrm{x}$

v. 5de ese alto imperio de siglos. $\mathrm{x} x \dot{x} / \mathrm{xx́x} / \mathrm{xx́x}$

v. 6Rueda el cielo - el aliento le corona x́x/ ́́x/ xx́x/ xxx́x

v.7 de agua mansa en palacios $\dot{\mathrm{x}} \mathrm{x} / \dot{\mathrm{x}} \mathrm{x} / \mathrm{x} \dot{x} \mathrm{x}$

v. 8 silenciosos sobre el río $\mathrm{xxx́x} / \mathrm{xx} x \dot{x}$

v.9 a decir su imagen clara $\mathrm{xxx́} / \mathrm{x} x \dot{x} / \mathrm{x} \mathrm{x}$

v.10 Su imagen clara. $\mathrm{x} \dot{x} \mathrm{x} / \dot{\mathrm{x} x}$

v.11 Va el cielo a presumir $\mathrm{x} \mathbf{x} \mathrm{x} / \mathrm{xx} \dot{x}$
(9 sílabas)

(7 sílabas)

(11 silabas)

(8 sílabas)

(8 sílabas)

(11 sílabas)

(7 sílabas)

(8 sílabas)

(8 sílabas)

(5 sílabas)

(6 sílabas)

v.12 - los mastines desvelados contra el viento-

(12 sílabas) 
xxx́x/ xxx́x/ xxx́x

v.13 de un aroma aconsejado. $\mathrm{xx} \dot{x} \mathrm{x} / \mathrm{xx} \dot{x} \mathrm{x}$

v.14 Rueda el cielo

$\dot{\mathrm{x}} \mathrm{x} / \dot{\mathrm{x} x}$

v.15 sobre ese aroma agolpado $\mathrm{xxx} \mathbf{x} \mathrm{x} / \mathrm{x} \dot{x} \mathrm{x}$

(8 sílabas)

(4 sílabas)

(8 sílabas)

v. 16 en las ventanas, XXXX́x

(5 sílabas)

v.17 como una oscura potencia XXXX́x/ Xx́x

v.18 desviada a nuevas tierras. $\mathrm{x} \dot{x} \mathrm{x} / \dot{x} \mathrm{x} / \dot{x} \mathrm{x}$

v.19 Rueda el cielo x́x/ ́x

(8 sílabas)

(7 sílabas)

(4 sílabas)

v.20 sobre la extraña flor de este cielo,

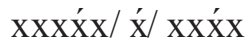

v.21 de esta flor, $\mathrm{xxx}$

v.22 única cárcel: x́xx/ x́x

(10 sílabas)

(3 sílabas)

(5 sílabas)

v. 23 corona $\sin$ ruido. xx́x/ xx́x

(6 sílabas)

En primera instancia, observamos que hay un predominio de versos de arte menor. De la presencia de aquel par de endecasilabos y el dodecasílabo se infiere que operan como intercalaciones que aportan mayor complejidad estructural al poema. Por otro lado, habiendo advertido los grupos ritmicos, hallamos una serie de paralelismos en el verso 1, 6, 14 y 19. El esquema sintáctico en repetición, "Rueda del cielo", evidencia una intención ligada a la circularidad, es decir, que alude a la cuestión del retorno ideológico tomando como base la serie de metáforas que se construyen a lo largo del texto. Distinguimos, además, una equivalencia fonética entre el verso 9 y 10. Esa "imagen clara" refuerza la imagen de aquel cielo rodante desplazándose por diversos espacios naturales. En este sentido, hay una frecuente referencia a las figuras en movimiento. Otro aspecto 
remarcable lo encontramos en los hemistiquios que aparecen en los versos 8, 11, 13, 14 y 23. La fuerza acentual de los grupos

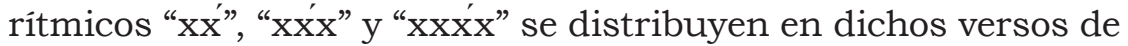
tal manera que realizan la simetría en estrecha relación con el contenido del poema: el sistema del mundo dividido en cielo y tierra. Una equivalencia semántica que sustenta lo anteriormente dicho reside en una particular representación de la flora — "flor", "clavel"-, en la cual se hace énfasis a su fragilidad y a su misticismo.

\section{E1 caso de "Hai kai en gerundio"}

El poema forma parte de poemas no publicados en libros. Lo hemos considerado en último lugar puesto que se evidencia ya la conciencia de una plena escritura lírica enfocada en elaborar un discurso alternando registros diversos, verbigracia, versos de arte mayor y arte menor. Ello quiere decir que, en este texto, prevalece una combinación entre lo popular y lo culto, como si fuera un diálogo conformado por el canto oral y el versolibrismo. Presentamos el poema en las siguientes líneas:

\begin{tabular}{|c|c|}
\hline 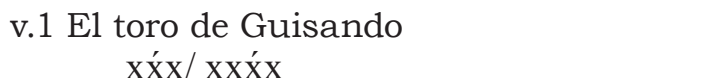 & (7 sílabas) \\
\hline $\begin{array}{l}\text { v.2 no pregunta cómo ni cuándo, } \\
\text { xxx́x/ x́x/ xx́x }\end{array}$ & (9 sílabas) \\
\hline $\begin{array}{l}\text { v.3 va creciendo y temblando. } \\
\text { xxx́x / xx́x }\end{array}$ & (7 sílabas) \\
\hline $\begin{array}{l}\text { v. } 4 \text { ¿Cómo? } \\
\text { X́x }\end{array}$ & (2 sílabas) \\
\hline $\begin{array}{l}\text { v.5 Acariciando el lomo } \\
\text { xxxx́x/ x́x }\end{array}$ & (7 sílabas) \\
\hline $\begin{array}{l}\text { v.6 del escarabajo de plomo, } \\
\text { xxxxx́x/ xx́x }\end{array}$ & (9 sílabas) \\
\hline 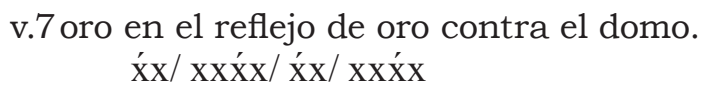 & (12 sílabas) \\
\hline v. 8 ¿Cuándo? & (2 sílabas) \\
\hline
\end{tabular}


v.9 En el muro raspando, $\mathrm{xxx́x} / \mathrm{x} x \mathbf{x}$

v.10 no sé si voy estando $\mathrm{xx} / \mathrm{x} \dot{x} / \mathrm{x} \mathrm{x}$

$\mathrm{v} .11$ o estoy ya entre los aludidos $\mathrm{xx} / \mathrm{x} \mathrm{x} / \mathrm{xxx} \mathrm{x́}^{\mathrm{x}}$

v.12 de Menandro. Xxx́x

v.13 ¿Cómo? ¿Cuándo? $x^{\prime} \mathrm{x} / \mathrm{x} \mathrm{x}$

v.14 Estoy entre los toros de Guisando, $\mathrm{xx} / \mathrm{xxx} \mathrm{x} / \mathrm{xxx} \mathrm{x}$

(7 sílabas)

(6 sílabas)

(9 sílabas)

(4 sílabas)

(4 sílabas)

(10 sílabas)

v.15 estoy también entre los que preguntan $\mathrm{xx} / \mathrm{xx} / \mathrm{x} \mathrm{x} / \mathrm{xxx} \mathrm{x}^{\mathrm{x}}$

v.16 cómo y cuándo. $\mathrm{x} x / \mathrm{x} x$

v.17 Creciendo y raspando, $\mathrm{xx} x$ / $\mathrm{xxx} x$

v.18 temblando.

$\mathrm{xx} x$

(11 sílabas)

(4 sílabas)

(6 sílabas)

(3 sílabas)

Antes de iniciar con el estudio del poema debemos hacer una pequeña digresión respecto a lo expresado en su título. El hai kai es una forma de poesía tradicional japonesa compuesta por pentasílabos y heptasílabos. Conocer esta acepción nos permite entender una de las intenciones artísticas de Lezama Lima, la cual consiste en diseñar vasos comunicantes entre la tradición y la modernidad. No obstante, el poeta cubano añade a esto el componente de la oralidad. Mediante la escansión identificamos que tanto el verso 4 como el 18 operan a partir de lo minimum relación al impulso métrico (Belic, 2000) y el predominio de los versos de arte menor.

El paralelismo percibido en los versos 4, 8, 13 y 16 se corresponden también con el concepto de equivalencia fonética. La repetición de estos sonidos acaso podría implicar la idea del estribillo, lo cual nos remitiría a la composición de una canción. A esto se le puede agregar la cuestión del retorno ideológico. 
Lo comprendido como "creciendo y temblando" forma parte del inicio, pero también de la conclusión del poema. De la disposición de los acentos podemos aseverar que, así como lo señala el título del poema, hay una predilección por el empleo de los verbos gerundios que permiten englobar la cadencia a lo largo de los versos. Por último, destacamos el despliegue de la rima consonante. Esto se constata en los versos 5, 6 y 7 partiendo de las flexibilidades del sonido de la /o/ — "plomo", "lomo", "domo". De modo que la consonancia utilizada connota una fluctuación entre lo popular, lo tradicional y lo oral.

El resultado de haber examinado tres textos que constituyen el universo lírico de Lezama Lima, a partir de su versificación, nos ha permitido advertir un carácter fluctuante y reiterativo entre lo clásico y lo moderno. El empleo de un estilo intertextual que integra el entramado de distintos registros poéticos y formas métricas incita a afirmar que el poeta cubano se nutre simultáneamente de la tradición y de lo que se tenía entendido como poesía durante su tiempo. Esto es en, definitiva, una heterogeneidad artística que continúa siendo paradigmática respecto a cómo realizar una lectura latinoamericana de las fuentes occidentales.

\section{Conclusiones}

José Lezama Lima ha elaborado un vasto sistema poético que muestra, como uno de sus objetivos primordiales, la unión de la estética clásica con la contemporánea. Mediante el análisis de las formas empleadas que estructuran sus poemas, hemos advertido la presencia de un arte que, habiendo asimilado las culturas antiguas, quiere convertirse en uno nuevo. En ese sentido, la principal innovación lezamiana recaería en que, partiendo del versolibrismo hasta bordear el versículo, consigue concebir un artefacto literario el cual, siendo tributario, se consolida como una lírica heterogénea que replantea y resemantiza lo heredado. Y esto vendría a ser una de uno de los rasgos fun- 
damentales del ethos artístico latinoamericano: asimilar una tendencia para luego transformarla.

A partir de lo discutido sobre los postulados teóricos de la versología moderna, se puede afirmar que el tema de la originalidad del verso libre y su aparente deslinde total con la métrica clásica debe ser frecuentemente abordado. Los estudios nos han ido demostrando que la propuesta de la vanguardia tiene sus antecedentes en las medidas expresivas de la antigüedad. En ese sentido, es posible afirmar que, a raíz del análisis del poema lezamiano como texto neobarroco y post vanguardista, el fenómeno artístico desatado en la década del 20 del siglo pasado, fue más el inicio de una actualización del orden que una escisión absoluta con todo lo anteriormente concebido en las esferas de la poesía.

\section{Referencias bibliográficas}

Belic, O. (2000). Verso español y verso europeo. Introducción a la teoría del verso español en el contexto europeo. Santafé de Bogotá: Instituto Caro y Cuervo.

Chamorro Agudelo, A. (2009). Muerte de Narciso: la fluidez de la imagen. (Tesis de licenciatura en Estudios Literarios), Pontificia Universidad Javeriana. Facultad de Ciencias Sociales, Bogotá. https://core.ac.uk/download/pdf/71420046.pdf

Del Río Surribas, J. (2005). Lezama Lima: infinitos ojos táctiles. El tacto como sentido del conocimiento. En Eva Valcárcel (ed.). La literatura hispanoamericana con los cinco sentidos España: Editorial Universidad de La Coruña, pp. 197 - 204. https://ruc.udc.es/dspace/bitstream/handle/2183/11355/ CC-78\%20art\%2020.pdf

Díaz, V. (2015). Barroco y modernidad en la teoría estética del siglo $X X$. (Tesis de Doctorado en Literatura) Universidad de Buenos Aires. Facultad de Filosofía y Letras, Buenos Aires. http:// repositorio.filo.uba.ar/bitstream/handle/filodigital/4666/ uba_ffyl_t_2015_69748.pdf?sequence=1\&isAllowed=y 
Ehrmannová, M. (2016). Las imágenes en el poema "Muerte de Narciso" de José Lezama Lima. (Tesis de Bachillerato en Literatura Latinoamericana). Univerzita Palackého v Olomouci. Facultad de Filosofía, República Checa. https://theses.cz/id/ zibmc5/18844648

Fernández-Cozman, C. (2001). Lectura estilística de "Enemigo rumor” (1941). Escritura y Pensamiento: Año IV, nro. 7, pp. 99 107. https://revistasinvestigacion.unmsm.edu.pe/index.php/ letras/article/view/7543/6562

Henríquez Ureña, P. (2003). Obras completas. Tomo III: Estudios Métricos. Santo Domingo: Secretaría de Estado de Cultura. Editora Nacional.

Jauralde Pou, P. (2004). Verso libre y verso irregular. Voz y letra, $\mathrm{XV} / 2$, pp. 115 - 128.

Lezama Lima, J. (2016). Poesía completa. Barcelona: Editorial Sexto Piso.

Martínez Cantón, C. (2019). El silencio del verso. La pausa y sus implicaciones métrico-estilísticas. Rythmica XVII, pp. 55 81. http://revistas.uned.es/index.php/rhythmica/article/ view/26320/20888

Paraíso Almanso, I. (1985). El verso libre hispánico. Orígenes y corrientes. Madrid: Gredos.

Paraíso Almanso, I. (2000). La métrica española en su contexto romántico. Madrid: Arco Libros.

Portuondo Valdor, J. (2005). Historia de la literatura cubana. Tomo II: La literatura cubana entre 1899 y 1958. La república. La Habana: Editorial Letras Cubanas.

Pozuelo Yvancos, J. (1989). Teoría del lenguaje literario. Madrid: Editorial Cátedra.

Ríos Sánchez, A. (2011). El mito de la muerte de Narciso en Ovidio, Valéry y José Lezama Lima: poética de la trascendencia en el poder transformador de la palabra. Káñina. Revista de Artes Letras por la Universidad de Costa de Rica, XXXV (1), pp. 27 39. https://www.redalyc.org/pdf/442/44248789003.pdf

Sarduy, S. (1969). Ensayos generales sobre el barroco. Buenos Aires: Editorial Sudamericana. 
Santos Gallardo, A. (2011). Barroco americano e intertextual en "Muerte de Narciso", de José Lezama Lima. ISLAS, 53 (166), pp. 21 - 29. http://islas.uclv.edu.cu/index.php/islas/article/ view/227/213

Utrera Torremocha, V. (2003). Ritmo y sintaxis en el verso libre. Rhythmica I, 1, pp. 303 - 333. http://revistas.uned.es/index. php/rhythmica/article/view/3958/3817

Utrera Torremocha, V. (2004). Tipografía y verso libre. Rhythmica, II, 2, pp. 251 - 273. http://revistas.uned.es/index.php/rhythmica/article/view/6410/6138 